\title{
An Empirical Investigation of the Factors Influencing Formal and Informal Employment in the City of Asmara
}

\author{
Fitsum Ghebregiorgis ${ }^{1} \&$ Habteab Tekie Mehreteab ${ }^{2}$ \\ ${ }^{1}$ Department of Business Management and Marketing, College of Business and Economics, Eritrea \\ ${ }^{2}$ Department of Economics, College of Business and Economics, Eritrea \\ Correspondence: Fitsum Ghebregiorgis, E-mail: fitadiam@gmail.com
}

Received: February 11, 2018; Accepted: March 8, 2018; Published: April 28, 2018

\begin{abstract}
This study investigates the factors influencing formal and informal labour market in Asmara, the capital city of Eritrea. The findings reveal that variables such as age, gender, education and birth place influence formal and informal labor market of the city. The chances for young people getting jobs in formal are low relative to older people. Higher educational level is related to securing jobs in the formal sector. Regarding gender males have more chances in the formal sector than females. People from Maekel/Central Region (townships surrounding Asmara) have higher chances to engage in self-employment. Generally, the results reveal that the labor market in Asmara show varied characteristics.
\end{abstract}

Keywords: formal, informal, employment, developing country, Eritrea

\section{Introduction}

\subsection{Background and Empirical Literature}

As far as, urban labor markets in developing countries are concerned, it is generally classified as formal and an informal sector (Pradhan and van Soest, 1995). The informal sector includes all jobs in informal sector enterprises. According to (OECD, 2009), informal sector was mainly considered as characteristics of developing countries and it was assumed that it would disappear as these countries economy develops.

Mazumdar (1989) describes an urban labor market structure in a typical developing country as being subdivided into three main categories: the formal sector, informal sector and the unemployed. Similarly, the International Labor Organization (ILO) also categorizes employment in the informal sector as: "employment in the informal sector" and "informal employment" with the informal sector being the largest sector in many countries (ILO, 2002).

The question that is central at formal or informal work is whether individuals choose to work in the informal sector or they opt to work in the sector as the only alternative at their disposal. The former considers employment in the informal sector to be supply-led and voluntary (Heckman and Sedlacek 1985; Malony 2004; Packard 2007); while the latter views informal work as a secondary market where all those without access to the primary formal market find themselves (Fields, 1990).

Fields (2005) also expanded the debate by presenting a third feature of the informal sector stating as a 'last resort sector', a 'desirable sector', and with 'internal dualism' combining the first two. Heterogeneity in the formal and informal sectors was usually done by distinguishing labor inside the formal and informal sector according to employment type as well as position in earning distribution (Arias and Khamis 2008; Bargain and Kwenda, 2009; Nguyen et al. 2011; Tansel and Kan, 2012; Harati, 2013). As aforementioned informal sector is crucial for the functioning of the labor market, since it affects income distribution (inequality) and poverty with implications for efficiency in terms of allocation of labor. This explains why the role of the informal sector has recently been analyzed extensively.

What strategies should be in place to enable government in developing countries to generate new employment and income opportunities and reduce informality and unemployment? In this regard, the need to create employment opportunities in Eritrea is underscored by the fact that the size of the informal market has been growing faster due to several economic and social issues. 
There are various research reports on the determinants of labor market participation and labor market modeling. This work has generally modified with the three strands of labor market namely formal sector, self-employed informal sector participants and informal wage earners.

Several scholars using logit, random utility, and ordinary least square (OLS) models conducted research in various countries including Guinea, Kenya, Ghana, Tanzania, Morocco, Cameroon, Burkina Faso, Mexico, and Pakistan. Their research findings show that higher the more a person is educated the more he/she can be employed in the formal sector (Glick and Sahn, 1997; Mariara, 2003; Rankin et al., 2010; Amin et al., 1995; Irfan, 1983; El Aynaoui, 1997; Traore, 2013; Faridi, 2011; Gong et al., 2000). However, this doesn't mean that other variables do not have any influence in the determination of labour market. For instance, age and place of residence determine whether a person chooses the formal or informal sector.

The main objective of this study is to investigate the factors that influence the formal and informal labor market in Eritrea. We employed multinomial logit model by dividing the labor market participation into formal employment (private and public) and informal employment. The specific objectives of this study are: What are the factors that influence labor market in Eritrea? What are the occupational choice determinants of an individual on the labor market?

\section{Methodology}

This study investigates the determinants of formal and informal labour market based on data collected from the metropolitan area of Asmara, Eritrea. In conducting this study, primary and secondary data have been used. Primary data were collected from individual residents of the city using survey questionnaire. A total number of 1200 questionnaires were distributed. Of the entire distributed questionnaire, we obtained 1080 correctly completed usable questionnaires, which is $90 \%$ response rate. Individuals were requested to give information related to their participation in the labor market. Moreover, relevant socioeconomic and demographic characters of the individuals were also collected.

This is helpful to estimate the probability of being in each employment type and allows for the marginal impact of explanatory variables to vary across the employment types. This study provides a practical explanation of the different determinants for the employment choices. Thus, the study employs a quantitative approach for the purpose of examining magnitudes of the effects of various factors. Data collected were analyzed and interpreted by using SPSS version 23 and multinomial logit (MNL) regression model.

\section{Data Analysis}

The data gathered has been analyzed using logit model, which is the most common method of describing how individuals choose between different occupational choices. As mentioned above, in this study individuals are sorted into three labor force categories, formal employment (private and public), informal self-employment and informal wage employment in informal and formal enterprises. The model allows the dependent variables to take three mutually exclusive and exhaustive values, $\mathrm{j}=0$ (formal employment), 1 (informal self-employment), or 2 (informal wage-employment). The explanatory variables used include the individual's socioeconomic and demographic characteristics such as age, gender, marital status, level of education, household size, religion, birth place, ethnicity and income.

In this paper, we use latent utility function framework to analyze the characteristics of occupational choice in the case of Asmara metropolitan area residents and to look for relationships that the above mentioned characteristics such as sex, age, education, income and others have with the individual's choice of a sector. The results can be used to find, understand and compare the attractiveness of each choice and determine the reasons and motives behind each of these choices.

The designing of choice model needs extensive evaluation of observed data and the efficiency of the whole model system. In the current study, specific parameters are predicted to impact individuals' behavior, when individuals have different choices. These requirements consist of the parameters such as gender (Gender), educational (Education) level, age (Age), household size (HHSize), marital status (Mstatus), religion (Religion) and birth place (BirthPlace) of the respondent (respondents are categorized based on their birth place from one to four being (Asmara $=1$; Maekel Region $=2$; other Eritrean Regions $=3$ and born outside of Eritrea $=4$ ).

\section{Discussion of Results}

\subsection{Descriptive Analysis}

The data comprises of 1080 respondents and $44.8 \%$ of these are females. Out of the total respondents, 545 are formal employees, 291 are informal self-employees and 244 are informal wage employment in informal and formal 
enterprises. The mean age of respondents is 36.7 years with minimum of 12 years and maximum of 75 years. Low minimum age reflects that there are young and poor respondents who work in the informal self-employment sector working as petty retailers. Table 1 below presents summary of respondents.

Table 1. Summary Statistics

\begin{tabular}{lll}
\hline Sector of Employment & Frequency & Percent \\
\hline Formal Employees & 545 & 50.5 \\
Informal Self-employees & 291 & 26.9 \\
Informal wage employees & 244 & 22.6 \\
\hline Total & $\mathbf{1 0 8 0}$ & $\mathbf{1 0 0}$ \\
\hline Socio-economic status & & \\
Gender & Frequency & Percent \\
Male & 596 & 55.2 \\
Female & 484 & 44.8 \\
\hline Total & $\mathbf{1 0 8 0}$ & $\mathbf{1 0 0 . 0}$ \\
\hline
\end{tabular}

Table 2. Age Statistics

\begin{tabular}{ll}
\hline Mean & 36.7 \\
\hline Standard Deviation & 13.66 \\
Minimum Age & 12 \\
Maximum Age & 75 \\
\hline
\end{tabular}

In doing the analysis, the formal employment was used as a base (reference) so that the other two choices (selfemployment and informal wage employment) were compared to this base. The model summary as presented in Table 3 shows a Likelihood Ratio value of 265.683 which is significant at the 0.0001 level. The Pseudo R-squared values (Cox and Snell and Nagelkerke) of 0.218 and 0.250 reveal the model is useful in predicting the employment choice of respondents. Table 2 and table 3 provide further details.

Table 3. Model Summary

\begin{tabular}{lllll}
\hline Model & Fitting criteria & Likelihood Ratio Tests & & \\
\hline Intercept only & 21.98051 & Chi-square & Df & Significance \\
Final & 19.52990 & 245.061 & 22 & 0.0001 \\
The Goodness-of -Fit & & & \\
Pearson & 2084.236 & 2024 & 0.172 \\
Deviance & 1921.113 & 2024 & 0.993 \\
Pseudo R-squared & Cox and Snell & Nagelkerke & McFadden \\
& & 0.203 & 0.232 & 0.110 \\
\hline
\end{tabular}

Table 4. Classification

\begin{tabular}{|c|c|c|c|}
\hline \multirow[b]{2}{*}{ Observed } & \multicolumn{3}{|l|}{ Predicted } \\
\hline & FormalSelf-en & dInform & sPercent Correct \\
\hline Formal & 462 & 22 & $84.8 \%$ \\
\hline Self-employed & 140 & 33 & $40.5 \%$ \\
\hline Informal wage employee & s166 & 37 & $15.2 \%$ \\
\hline Overall Percentage & $71.1 \% 20.4 \%$ & $8.5 \%$ & $57.1 \%$ \\
\hline
\end{tabular}

The regression results as presented in Table 5 shows that some of the determinants such as age (Age), gender (Gender), birth place (Birthplace), marital status (Marital Status) household size (Hosueholdsize), education (Education) and religion (Religion) statistically affect the probability of a respondent choices of sector of employment in the labor market. 
Table 5. MNL results for labor market choice

\begin{tabular}{|l|l|l|l|l|l|l|l|l|}
\hline & \multicolumn{4}{|l|}{ Self-employment } & \multicolumn{4}{l|}{ Informal wage employment } \\
\hline Variables & Coefficient & $\begin{array}{l}\text { Std. } \\
\text { error }\end{array}$ & Sig. & $\begin{array}{l}\text { Odds } \\
\text { Ratio }\end{array}$ & Coefficient & $\begin{array}{l}\text { Std. } \\
\text { error }\end{array}$ & Sig. & $\begin{array}{l}\text { Odds } \\
\text { Ratio }\end{array}$ \\
\hline Intercept & 3.453 & 0.797 & $0.0001^{*}$ & & 2.035 & 0.950 & 0.032 & \\
\hline Age & -0.029 & 0.007 & $0.0001^{*}$ & 0.971 & -0.041 & 0.007 & $0.0001^{*}$ & 0.960 \\
\hline Gender & -0.353 & 0.168 & $0.035^{*}$ & 0.702 & -0.615 & 0.169 & $0.0001^{*}$ & 0.541 \\
\hline Education & -0.240 & 0.026 & $0.0001^{*}$ & 0.786 & -0.207 & 0.026 & $0.0001^{*}$ & 0.813 \\
\hline Marital Status & -0.472 & 0.502 & 0.347 & 0.624 & 0.981 & 0.605 & 0.105 & 2.666 \\
\hline Hosueholdsize & -0.044 & 0.035 & 0.205 & 0.957 & -0.041 & 0.036 & 0.254 & 0.960 \\
\hline BirthPlace(2) & 1.249 & 0.530 & $0.019^{*}$ & 3.489 & 0.522 & 0.632 & 0.410 & 1.685 \\
\hline Religion & 0.215 & 0.229 & 0.349 & 0.807 & -0.053 & 0.241 & 0.826 & 0.948 \\
\hline
\end{tabular}

The reference category is Formal Employment

* Statistically significant at 5\% significance probability level

The above table shows the most acceptable model. Some of the models that were analyzed have revealed inadequate statistical goodness of-fit and/or had counter-intuitive signs; and therefore were invalidated and discarded. As stated previously, the basic idea behind the mode choice estimation was to identify factors influencing respondents' choice between formal and informal sector employment. Greater parts of the variables presented have significant parameter estimates.

Of the specific parameters used to predict the choice of sector employment, the demographic variable age $(A g e)$ is important for these two informal subsectors (informal self-employment and informal wage employment) of employment. The result is significant with a negative coefficient implying that the likelihood of people to be employed in these informal subsectors decreases with age. The odds ratios are also below one supporting the argument. As age is related to experience, this result concurs with Goldar (2010), where generally older individuals are preferred in the formal labor market.

Gender (Gender) variable has a negative coefficient and is statistically significant in the informal self-employment and informal wage employment sub-sectors and it's odds ratio is less than one. This implies that the chances for males in the informal self-employment and informal wage employment subsectors are low. The result simply shows that the majority of males have high probability of working in the formal sector compared to females for the simple fact that males face fewer barriers related to qualification and discrimination. In addition, some women may prefer the informal sector in order to cope with the need to care for children and domestic chores to the extent that this sector enables them to combine productive and reproductive work.

Regarding Education variable, the coefficient of is negative and significant. The negative effect of education on these two subsectors implies that having better education diminishes the chances of being employed in these two subsectors or enhances the opportunity for working in the formal sector. This chance increases with the level of education and is therefore higher for university education. The odds ratios are also below one supporting the argument.

Finally, Birthplace variable is introduced to explain the labor market choice behavior of the respondents. The result was found to be positive and significant for the category (Maekel Region) indicating that the probability of employment in informal self-employment sector increases for those who are born in this Region. Maekel (central) is one of the six regions of Eritrea and the city of Asmara is located in this region. Residents of this region have easy access to the city as they live from fifteen to thirty kilometers away from the city. In the pick seasons they work in their farms and during slack seasons they come to the city to do some informal self-employment activities.

\section{Conclusions and Implications}

The main goal of this paper is to assess the variables that determine the choice of employment in the formal/informal sector in the metropolitan area of Asmara. As discussed in the aforementioned section, four variables-Age, Gender, Education and Birth place are important in determining the sectorial choice. That is, variable age (statistically significant with a negative coefficient); gender (negative coefficient and is statistically 
significant); the coefficient of education variable is negative and significant; and the result of birth place variable was found to be positive and significant for the category (Maekel Region).

In general, formal sector employment in both public and private sectors is male-dominated while women occupy the inferior informal sector (inferior in the sense of low incomes, precarious tenure and unregulated forms of employment). Regarding formal employability of workers, improving quantity and quality of education is important as an enabling instrument. In pursuit of educational achievements, gender imbalance has to be addressed as a way of increasing professionalism of women and to emancipate them from being preys of informal employers.

This study raises many questions for further research while identifying education and employment policy gaps: What specific skills or qualities do employers look for when recruiting new employees? Is the current education system demand or supply driven, and does it equip graduates with adequate skills to become self-employed? In addition, a great concern is to identify whether gender discrepancy is a result of labor market discrimination against or is justified on the basis of human capital skills. Answers to these questions have broad policy implications towards an achievement of gender balance in education, the labor market and poverty eradication.

Our study is not without limitations. This study focuses on the supply factors only excluding the demand side. A thorough understanding of the demand would be necessary to complement such a study, but relevant data on the demand side are lacking. Future research and survey data collection methodologies should incorporate the demandside information.

\section{References}

Amin, R., Robert, B. H., \& Li, Y. P. (1995). Poor Women's Participation in Credit Based Self-employment: The Impact on their Empowerment, Fertility, Contraceptive Use and Fertility Desire in Rural Bangladesh", The Pakistan Development Review, 34(2).

Arias, O., \& Khamis, M. (2008). Comparative Advantage, Segmentation and Informal Earnings: A Marginal Treatment Effects Approach, IZA Discussion Papers No.391.

Bargain, O., \& Kwenda, P. (2009). The Informal Sector Wage Gap: New Evidence Using Quantile Estimations on Panel Data, IZA Discussion Papers No.4286.

El Aynaoui, J. (1997). Participation, Choix Occupationnel et Gains Sur un Marché du Travail Segmenté: uneAnalyseAppliquée au Cas du Maroc, Centre d'économie du développement, Université MontesquieuBordeaux IV-France.

Faridi, M. Z., Chaudhry, I. S., \& Malik, M. S. (2011). Why Women are Self-Employed? Empirical Evidence from Pakistan, International Journal of Economics and Finance, 3(1). https://doi.org/10.5539/ijef.v3n1p198

Fields, G. (2005). A Guide to Multi-sector Labor Market Models, World Bank Social Protection, Discussion Paper Series No. 0505, World Bank, Washington D.C.

Fields, G. S. (1990). Labor Market Modeling and the Urban Informal Sector: Theory and Evidence, In D. Turnham, Salome, B., Schwarz, A., eds., The Informal Sector Revisited, Paris, OECD.

Glick, P., \& Sahn, D. E. (1997). Gender and Education Impacts on Employment and Earnings in West Africa: Evidence from Guinea, Economic Development and Cultural Change, 45(4), 793-823. https://doi.org/10.1086/452308

Goldar, B. (2010). Informalization of Industrial Labor in India: Are Labor Market Rigidities and Growing Import Competition to Blame? Working Paper No. id: 3125, Social Sciences. Retrieved from https://ideas.repec.org/p/ess/wpaper/id3125, html.

Gong, X., Soest, A. V., \& Villagomez, E. (2000). Mobility in the Urban Labor Market: A Panel Data Analysis for Mexico, the Institute for the Study of Labor (IZA) in Bonn, Discussion Paper No. 213, November 2000.

Harati, R. (2013), Heterogeneity in the Egyptian Informal Labor Market: Choice or Obligation? CES Working Papers no. 2013.32, Centre d'Economie de la Sorbonne, Universit'e Paris I Pantheon-Sorbonne.

Heckman, J., \& Sedlacek, G. (1985). Heterogeneity, Aggregation and Market Wage Functions: an Empirical Model of Self-selection in the Labor Market, Journal of Political Economy, 93, 1077-1125. https://doi.org/10.1086/261352

ILO (2002). Decent Work and the Informal Economy: Sixth Item on the Agenda, International Labor Conference, Geneva.

Irfan, M., Khan, Z., Mubashir, S. A., Rafiq, M., \& Masood, A. (1983). The Determinants of Female Labor Force 
Participation in Pakistan, Islamabad, Pakistan Institute of Development Economics, Studies in Population, Labor Force and Migration Project, Report No 5.

Maloney, W. F. (2004). Informality Revisited, World Development, 32, 1159-1178. https://doi.org/10.1016/j.worlddev.2004.01.008

Mariara, J. K. (2003). Wage Determination and Gender Wage Gap in Kenya, Any Evidence of Gender Discrimination? Research Paper No. 132, African Economic Research Consortium, Nairobi.

Mazumdar, D. (1989). Microeconomic Issues of Labor Markets in Developing Countries: Analysis and Policy implications, EDI Seminar Paper, Economic Development Institute of the World Bank, Washington D.C. https://doi.org/10.1596/0-8213-1183-2

Nguyen, H. C., Nordman, C. J., \& Roubaud, F. (2011). Who Suffers the Penalty? A Panel Data Analysis of Earnings Gaps in Vietnam, Mimeo, DIAL, Paris.

Organization for Economic Co-operation and Development (OECD) (2009). Is Informal Normal? Towards More and Better Jobs in Developing Countries, Paris, OECD.

Packard, G. (2007). Do Workers in Chile Choose Informal Employment? A Dynamic Analysis of Sector Choice, Working Paper 4232, World Bank.

Pradhan, M., \& Soest A. V. (1995). Formal and Informal Sector Employment in Urban Areas of Bolivia, Labor Economics, 2, 275-297. https://doi.org/10.1016/0927-5371(95)80032-S

Rankin, N.,Sandefur, J., \& Teal, F. (2010). Learning and Earning in Africa: Where are the Returns to Education High, CSAE WPS/2010-02.

Tansel, A., \& Kan, E. O. (2012a). The Formal/Informal Employment Earnings Gap: Evidence from Turkey, ERC Working Papers in Economics 12/04, Economic Research Center, April.

Traore J. A. (2013). Revisiting the Determinants of Informal Sector in Burkina Faso, University Ouaga II, Laboratory of Economic Policy Analysis (LEPA), Online at http://mpra.ub.uni-muenchen.de/49006/ MPRA Paper No. 49006, posted 16. August 2013 15:53 UTC.

\section{Copyrights}

Copyright for this article is retained by the author(s), with first publication rights granted to the journal.

This is an open-access article distributed under the terms and conditions of the Creative Commons Attribution license (http://creativecommons.org/licenses/by/4.0/). 